\title{
ACE inhibition salvages the visual loss caused by diabetes
}

\author{
B. V. Bui ${ }^{1}$, J. A. Armitage ${ }^{1}$, M. Tolcos ${ }^{2}$, M. E. Cooper $^{2}$, A. J. Vingrys ${ }^{1}$ \\ ${ }^{1}$ Department of Optometry and Vision Sciences, University of Melbourne, Victoria, Australia \\ ${ }^{2}$ Department of Medicine, University of Melbourne, Austin and Repatriation Medical Center, West Heidelberg, Victoria, Australia
}

\section{Abstract}

Aims. We consider the nature of retinal dysfunction in streptozotocin rats and assess the functional benefits of administering an angiotensin enzyme inhibitor or an inhibitor of advanced glycation end product formation. Methods. Sprague-Dawley rats $(n=44)$ were randomly assigned to control $\left(\mathrm{C}=12, \mathrm{C}_{\mathrm{p}}=4, \mathrm{C}_{\mathrm{a}}=4\right)$ and diabetic groups (Streptozotocin, $\mathrm{D}=24$ ). Diabetes was diagnosed based on a range of physiological and biochemical parameters at 4,8 and 12 weeks. Streptozotocin animals were administered insulin daily (4 units protophane). Animals were treated with either an Angiotensin Converting Enzyme inhibitor (perindopril, $\mathrm{C}_{\mathrm{p}}=4, \mathrm{D}_{\mathrm{p}}=8$ ) or an inhibitor of advanced glycation end product formation (aminoguanidine, $\mathrm{C}_{\mathrm{a}}=4, \mathrm{D}_{\mathrm{a}}=8$ ). Dark-adapted electroretinograms were measured on anaesthetized animals at 12 weeks following streptozotocin treatment. Photoreceptoral and inner retinal responses were extracted, modelled and compared using ANOVA.
Results. Streptozotocin injection increased blood glucose, glycosylated haemoglobin, fluid intake and urine volume, whereas body weight was decreased. Perindopril treatment produced improvements $(p<0.05)$ in all indices, whereas aminoguanidine therapy produced some improvement in blood glucose and water intake. Streptozotocin rats showed losses of photoreceptoralP3 $(-27 \%)$, postreceptoral-P2 $(-15 \%)$ and oscillatory potential $(-19 \%)$ amplitudes of a similar magnitude. Perindopril therapy returned photoreceptoral and inner retinal function to within control limits. However, aminoguanidine treatment gave no significant functional improvement.

Conclusions. Our findings provide evidence for a selective neuropathy in diabetes with a primary photoreceptoral lesion. Treatment with perindopril, an angiotensin converting enzyme inhibitor, ameliorates the neuropathy. [Diabetologia (2003) 46:401-408]

Keywords Retina, ERG, ACE inhibition, streptozotocin, rats.
Diabetic retinopathy is a leading cause of blindness in working aged adults [1]. Much of the diabetes literature has focused on the vascular aspects of the disease,

Received: 27 June 2002 / Revised: 15 October 2002

Published online: 7 March 2003

(C) Springer-Verlag 2003

Corresponding author: A. J. Vingrys, Department of Optometry and Vision Sciences, University of Melbourne, Victoria, 3010, Australia

E-mail: a.vingrys@optometry.unimelb.edu.au

Abbreviations: ACE, angiotensin converting enzyme; ERG, electroretinography; OP, oscillatory potentials; $\mathrm{PKC}$, protein kinase cepsilon; RAS, renin-angiotensin system; STZ, streptozotocin. which is thought to cause altered neural function and consequently vision loss. Not surprisingly, treatments target the vascular lesions, which occur secondary to chronic hyperglycaemia, manifesting as diabetic retinopathy [1]. Scant attention has been paid to the neurodegenerative aspects of diabetes. However, an increasing body of work supports the view that neuropathy is an important component in the pathogenesis of diabetic retinopathy $[2,3]$.

Functional studies using the electroretinogram have shown that inner retinal dysfunction, in the form of oscillatory potential $[4,5]$, and pattern electroretinogram (ERG) defects in Type 1 diabetic patients precede the onset of visible vascular changes in the retina 
$[6,7,8]$. Similar oscillatory potential deficits have also been reported, soon after the induction of diabetes, in a rat model of Type 1 diabetes $[9,10]$. The above electrophysiological studies localize neuronal deficits to the inner retina; however, other studies report the presence of photoreceptoral dysfunction soon after diabetogenesis [11]. More recently, photoreceptor abnormalities have been found in diabetic humans, although vascular changes in these retinae complicates the interpretation of these findings [12].

Psychophysical measurements of color sensitivity $[13,14]$ have shown altered thresholds in diabetic patients without retinopathy. Additionally, nerve fibre loss and anomalies of glial cell function and glutamate metabolism have also been observed in diabetic rats [15]. In spite of the conflicting electrophysiological data, the above studies support the contention that neural dysfunction occurs independent of, or at least in conjunction with, the vasculopathy. Consistent with both vascular and neuronal involvement, modulation of the renin-angiotensin system has been shown to have a neuroprotective role $[16,17,18]$. Reduced levels of diabetic retinopathy have been reported using an Angiotensin Converting Enzyme (ACE) as an adjunct to traditional glucose control, in the HOPE multi-centre trial [17].

The streptozotocin (STZ) rat model of diabetes could serve as a useful model for considering the nature of retinal dysfunction in the diabetic retina prior to the advent of patent vasculopathy [19]. The following study examines photoreceptoral-P3 and inner retinal (postreceptoral-P2, oscillatory potentials) function in rats, 12 weeks following STZ injection. Additionally, we consider the effectiveness of an ACE inhibitor, known to have neuroprotective activity, at restoring any functional deficits induced by STZ treatment.

\section{Materials and methods}

All experimental protocols in this study were approved by our institutional ethics committee and conformed to the NHMRC Principles of Laboratory Animal Care. A cohort of 44 Sprague-Dawley rats (200-250 gm) were fasted overnight and randomized to receive either streptozotocin (STZ $50 \mathrm{mg} / \mathrm{kg}$, $\mathrm{D}=24)$ or citrate buffer $(C=20)$ by intravenous injection in the tail vein. Diabetes was diagnosed based on a range of physiological and biochemical parameters taken at 4, 8 and 12 weeks. These included: elevated blood glucose concentrations (>15 mmol/l), abnormal glycosylated haemoglobin $\left(\mathrm{HBA}_{1 \mathrm{c}}\right.$ $>7.0 \%$ ), polyuria ( $>40 \mathrm{ml}$ urine volume/24 h) and polydypsia ( $>60 \mathrm{ml}$ fluid intake/24 h). All STZ-treated animals were administered insulin daily (4 units of human protophane at 9 am) to mimic the human condition. Fluid intake and urine volume was collected using metabolic cages over a 24 -h period at time points described above. Body weight was measured weekly. Animals from each group $[\mathrm{C}=12$ (non STZ), D=8 (STZ-treated)] were used to evaluate the specific effects of the diabetic milieu, whereas the remaining animals were treated with drugs. Medication was with either an ACE inhibitor (perindopril, Servier Laboratories, Paris, France, $6 \mathrm{mg} / \mathrm{kg}$ : $\mathrm{C}_{\mathrm{p}}=4$,
$\mathrm{D}_{\mathrm{p}}=8$ ) or an inhibitor of advanced glycation end product formation (aminoguanidine, Regis Technologies, Morton Grove, Ill., USA, $800 \mathrm{mg} / \mathrm{kg}: \mathrm{C}_{\mathrm{a}}=4, \mathrm{D}_{\mathrm{a}}=8$ ). Medications were administered to animals via drinking water. The varying body weights and water intakes were taken into account in determining the appropriate drug dosage for control (perindopril, $0.6 \mathrm{mg} / \mathrm{ml}$ : aminoguanidine, $11 \mathrm{mg} / \mathrm{ml}$ ) and STZ treated (perindopril, $0.25 \mathrm{mg} / \mathrm{ml}$ : aminoguanidine, $4 \mathrm{mg} / \mathrm{ml}$ ) groups to equate drug intake. Our purpose for using the latter drug (aminoguanidine) was to include a group receiving an agent known to have vasoprotective effects without a strong neuromodulatory action. By contrasting the effects found with perindopril against those from aminoguanidine we can consider the hypothesis that ACE inhibition is acting via a neuroprotective mechanism.

Electroretinography. Retinal function was measured at 12 weeks following diabetogenesis with electroretinograms (ERG) collected over an ensemble of light intensities $(0.7$ to $2.5 \mathrm{log}$ $\mathrm{cd} \cdot \mathrm{s} \cdot \mathrm{m}^{-2}$ ) following overnight dark-adaptation ( $\left.>12 \mathrm{~h}\right)$. Animals were anaesthetized under dim red light $\left(\lambda_{\max }=650 \mathrm{~nm}\right)$ using a mixture of ketamine and xylazine $(60: 5 \mathrm{mg} / \mathrm{kg}$, Troy Laboratory, Frenchs Forest, NSW, Australia). Mydriasis ( $\geq 4 \mathrm{~mm}$ ) was achieved with tropicamide (Mydriacyl 0.5\%, Allergan, Frenchs Forest, NSW, Australia) and corneal anesthesia with proxymetacaine (Ophthetic 0.5\%, Allergan, Frenchs Forest, NSW, Australia). Flash ERGs (white) were recorded with silver-silver chloride electrodes referenced to a stainless steel ground inserted in the tail. Responses were amplified (gain $\times 1000 ;-3 \mathrm{~dB}$ at 0.1 and $3000 \mathrm{~Hz}$, P55 Grass instruments, West Warwick, R.I., USA) and digitized at $2 \mathrm{kHz}$. A commercial photographic flash unit (285 V, Vivitar Photographics, Newbury Park, Calif., USA) was delivered via a Ganzfeld sphere to produce an unfiltered photopic exposure of $3.5 \mathrm{log} \mathrm{cd} \cdot \mathrm{s} \cdot \mathrm{m}^{-2}$, which was attenuated using calibrated neutral density filters (Kodak Wratten, Eastman Kodak, Rochester, N.Y., USA).

Photoreceptoral function. The ERG waveform (Fig. 1A) is characterized by the negative going photoreceptoral response or a-wave followed by a positive postreceptoral deflection or b-wave on which can be seen many small oscillations (oscillatory potentials). For this study we model the leading edge of the a-wave using a modified computational description of the phototransduction cascade as given by Equation 1 [20],

$P 3(i, t)=R m_{P 3} \cdot\left[1-e^{-i \cdot S \cdot\left(t-t_{d}\right)^{2}}\right] \quad$ for $\mathrm{t}>\mathrm{td}$

where, P3 is the summed rod photocurrent as a function of luminous energy, i (cd.s. $\mathrm{m}^{-2}$ ) and time $\mathrm{t}(\mathrm{s})$ and $\mathrm{Rm}_{P 3}(\mu \mathrm{V})$ is its saturated amplitude. Sensitivity $\left(\mathrm{S}, \mathrm{m}^{2} \cdot \mathrm{cd}^{-1} \mathrm{~S}^{-3}\right)$ is scaled by $\mathrm{i}$, whereas $t_{d}(s)$ is a delay which includes biochemical and other recording latencies. This model was fitted to the raw data for an ensemble of luminous energies ( 0.7 to $\left.2.5 \mathrm{log} \mathrm{cd} \cdot \mathrm{s} \cdot \mathrm{m}^{-2}\right)$ up to the first minimum of each a-wave. The delay $t_{d}$ was fixed at $2.75 \mathrm{~ms}$ being the average value found in our normal group. Parameter optimization in all animals was achieved by floating $\mathrm{Rm}_{P 3}$ and $\mathrm{S}$ (fixed $\mathrm{t}_{\mathrm{d}}$ ), and minimizing the root-mean-square error term with the solver module of an Excel spreadsheet (Microsoft, Redmond, W.Va., USA). The model was applied to the raw data up to the minimum of each a-wave as shown by the symbols, whereas the lines represent the modelled response (Fig. 1B,C).

Inner retinal function. The postreceptoral-P2 component is generally believed to originate from the inner retina. The postreceptoral-P2 was exposed by digital subtraction of the modelled photoreceptoral P3 from the raw waveform (Fig. 2A) [21]. The isolated postreceptoral-P2 potential is subsequently 


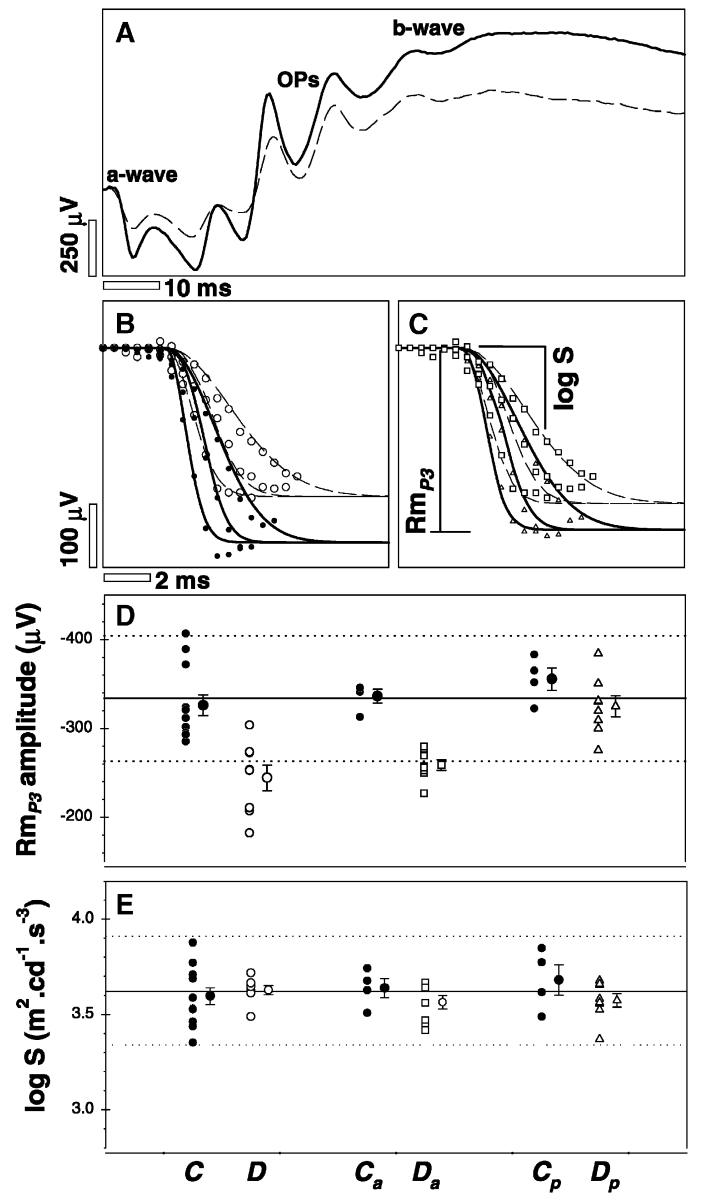

Fig. 1A-E. Photoreceptor function in diabetes is ameliorated with ACE inhibition. A Streptozotocin injected animals (broken line) showed reduction of electroretinogram responses compared with control animals (solid line). B The photoreceptoral response (symbols) was described using a computational description of the phototransduction cascade (lines). The loss of retinal function diabetic animals $(O$, dashed lines) compared with control rats $(\mathbf{O}$, solid lines) could be localized to a reduction in the photoreceptoral-P3 saturated amplitude $\left(\mathrm{Rm}_{P 3}\right)$. C Treatment with an ACE inhibitor (perindopril, $\triangle$, solid lines) resulted in full restoration of the photoreceptoralP3 amplitude, whereas an inhibitor of advanced glycation end product formation (aminoguanidine, $\square$, dashed lines) did not improve function. D The streptozotocin treated group $(\mathrm{D}, \mathrm{O})$ had smaller $\mathrm{Rm}_{P 3}$ than controls $\left(\mathrm{C}\right.$, left). Perindopril $\left(\mathrm{D}_{\mathrm{p}}\right.$, $\triangle$ ) treatment fully ameliorated streptozotocin induced photoreceptoral dysfunction, whereas aminoguanidine $\left(\mathrm{D}_{\mathrm{a}}, \square\right)$ showed no improvement. Both perindopril $\left(\mathrm{C}_{\mathrm{p}}\right.$, centre $)$ and aminoguanidine $\left(\mathrm{C}_{\mathrm{a}}, \bigcirc\right.$ right $)$ drugs had no effect on $\mathrm{Rm}_{P 3}$ in control animals. Reference lines show mean (solid) and 95\% confidence limits (dotted) of the mean control photoreceptoral-P3 amplitude. E Phototransduction sensitivity ( $\log \mathrm{S}$ ) was unaffected by streptozotocin treatment and showed no change with either perindopril or aminoguanidine therapy

described in terms of it baseline to peak amplitude and implicit time (stimulus onset to peak).

Oscillatory potentials were isolated by digitally subtracting the a-wave and b-wave from the raw data and band-pass filtering (55-250 Hz, 512-tap FIR filter, Blackman window) the resultant waveform [22]. Following OP extraction we modelled the data in the time domain using a Gabor function (Eq. 2c),

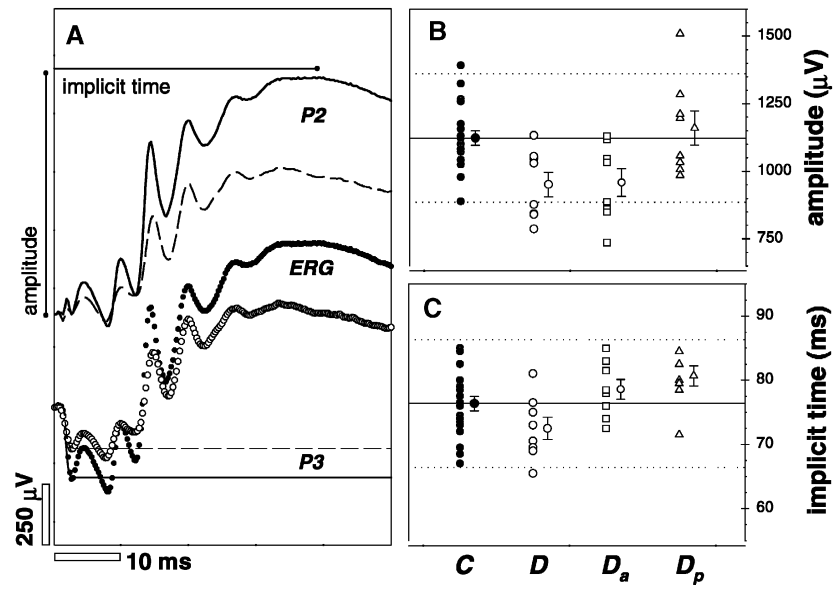

Fig. 2A-C. Inner retinal function in diabetes is ameliorated with ACE inhibition. A The postreceptoral-P2 response is derived following digital subtraction of the modelled photoreceptoral-P3 response from the raw ERG waveform (symbols). Streptozotocin injected animals (upper broken line) showed a reduction of P2 amplitudes compared with control animals (upper solid line). B Diabetic animals $(\mathrm{D}, \bigcirc)$ showed a loss of amplitudes compared with control rats $(\mathrm{C}, \mathbf{O})$. Treatment with an ACE inhibitor $\left(D_{p}\right.$, perindopril, $\triangle$ ) resulted in full restoration of postreceptoral-P2 amplitudes, whereas an inhibitor of advanced glycation end product formation $\left(\mathrm{D}_{\mathrm{a}}\right.$, aminoguanidine, $\square$ ) did not improve function. Reference lines show mean (solid) and 95\% confidence limits (dotted) of the mean control photoreceptoral-P3 amplitude. C The streptozotocin treated group had a trend for smaller postreceptoral-P2 implicit times than controls. Both perindopril and aminoguanidine treatment improved postreceptoral-P2 implicit times

which represents the multiplication of a gaussian envelope (Eq. 2a) with a sine wave carrier (Eq. 2b) [22].

$$
\begin{aligned}
& g(x)=a \cdot e^{-\frac{1}{2} \cdot\left(\left(\frac{x-m}{s}\right)^{2}\right)} \\
& f(x)=\sin 2 \cdot h \cdot x \cdot \pi+p
\end{aligned}
$$

$\operatorname{Gabor}(x)=g(x) \cdot f(x)$

As a function of time (x), the gaussian envelope (Eq. 2a) is described by its maximum amplitude (a, OP amplitude, $\mu \mathrm{V}$ ), peak envelope position ( $\mathrm{m}$, OP implicit time, $\mathrm{ms}$ ) and spread (s, ms). The sine wave carrier (Eq. 2b) is described by its frequency $(\mathrm{h}, \mathrm{Hz})$ and phase relative to the start of the waveform (p, degrees). Fitting was achieved by floating all parameters and minimizing the mean square error term using a LevenbergMarquardt optimization routine.

Statistics. Statistical comparisons were made for the main effects by ANOVA with a Fischer's PLSD post-hoc test used to identify differences between means. A $p$ value of 0.05 was considered statistically significant.

\section{Results}

Twelve weeks following STZ injections, treated rats developed characteristics typical of diabetes, showing increased blood glucose concentration, increased glycosylated haemoglobin, reduced body weight, as well 
Table 1. Physiological parameters for control and medicated diabetic rats

\begin{tabular}{|c|c|c|c|c|c|c|}
\hline Group & $n$ & $\begin{array}{l}\text { Blood glucose } \\
(\mathrm{mmol})\end{array}$ & $\begin{array}{l}\mathrm{HBA}_{1 \mathrm{c}} \\
(\%)\end{array}$ & $\begin{array}{l}\text { Urine volume } \\
\text { (ml / day) }\end{array}$ & $\begin{array}{l}\text { Water intake } \\
\text { (ml / day) }\end{array}$ & $\begin{array}{l}\text { Body weight } \\
\text { (mg) }\end{array}$ \\
\hline $\mathrm{D}(\mathrm{a})$ & 8 & $26.7 \pm 1.5^{b-f}$ & $10.8 \pm 0.9^{c-f}$ & $119.0 \pm 23.6^{\mathrm{c}-\mathrm{f}}$ & $158.6 \pm 28.3^{\mathrm{b}-\mathrm{f}}$ & $476.9 \pm 19.4^{\mathrm{b}-\mathrm{e}}$ \\
\hline$D_{p}^{a}(c)$ & 8 & $19.9 \pm 1.5^{\mathrm{a}, \mathrm{d}-\mathrm{f}}$ & $8.0 \pm 0.2^{\mathrm{a}, \mathrm{b}, \mathrm{d}-\mathrm{f}}$ & $76.1 \pm 13.3^{\mathrm{a}, \mathrm{d}-\mathrm{f}}$ & $91.9 \pm 12.5^{\mathrm{a}, \mathrm{d}-\mathrm{f}}$ & $425.4 \pm 10.0^{\mathrm{a}, \mathrm{d}-\mathrm{f}}$ \\
\hline $\mathrm{C}^{\mathrm{p}}(\mathrm{d})$ & 12 & $6.0 \pm 0.3^{\mathrm{a}-\mathrm{c}}$ & $3.8 \pm 0.2^{\mathrm{a}-\mathrm{c}}$ & $21.7 \pm 1.1^{\mathrm{a}-\mathrm{c}}$ & $48.8 \pm 2.1^{\mathrm{a}, \mathrm{b}}$ & $588.6 \pm 13.6^{\mathrm{a}-\mathrm{c}, \mathrm{f}}$ \\
\hline $\mathrm{C}_{\mathrm{a}}(\mathrm{e})$ & 4 & $5.8 \pm 0.2^{\mathrm{a}-\mathrm{c}}$ & $3.9 \pm 0.2^{\mathrm{a}-\mathrm{c}}$ & $18.3 \pm 2.7^{\mathrm{a}-\mathrm{c}}$ & $40.0 \pm 8.4^{\mathrm{a}, \mathrm{b}}$ & $553.8 \pm 11.8^{\mathrm{a}-\mathrm{c}}$ \\
\hline
\end{tabular}

Unmedicated STZ-treated (D) aminoguanidine medicated STZ-treated $\left(D_{a}\right)$ perindopril medicated STZ-treated $\left(D_{p}\right)$ unmedicated controls (C) aminoguanidine medicated controls $\left(\mathrm{C}_{\mathrm{a}}\right)$ and perindopril medicated controls $\left(\mathrm{C}_{\mathrm{p}}\right)$ groups are given.

as polyuria and polydypsia (Table 1). Aminoguanidine therapy in diabetic animals produced a reduction in blood glucose and water intake but failed to normalize these values to those of the control animals. Perindopril treatment of diabetic animals produced improvements in all indices, compared with the untreated diabetic group, except body weight (Table 1). The supply of both aminoguanidine and perindopril to control animals did not significantly alter any of the indices measured in this study.

STZ treatment induces a generalized retinal dysfunction. One of the findings of this study is that following STZ treatment, a loss of retinal function was observed as shown by the representative waveforms in Fig. 1A. This functional loss was particularly manifest in the photoreceptoral-P3 component of the ERG as shown by the representative phototransduction model fits (lines) to the raw data (symbols) in Fig. 1B. The photoreceptoral saturated amplitude $\left(\mathrm{Rm}_{P 3}\right)$ was reduced $(-27 \%, p<0.05)$ in diabetic animals (Fig. 1D, unfilled circles) compared with control animals (filled circles). However, no significant change in phototransduction sensitivity $(\log S)$ was observed in STZ animals [Fig. 1E, ANOVA $F_{3,32}=0.56 p=0.64(0.15)$ ].

Consistent with abnormalities in photoreceptoral function, Fig. 2 shows that STZ treatment animals had smaller postreceptoral responses (solid line, unfilled circles) compared with control animals (dashed lines, filled circles). Further, the amplitude of the postreceptoral-P2 response was smaller $(p<0.05)$, whereas implicit times were unaltered $(p=0.28)$ in diabetic rats compared with control rats. Average postreceptoral-P2 amplitude loss in the STZ group was approximately $-15 \%(951.3 \pm 45.5$ vs $1079.6 \pm 31.6 \mu \mathrm{V})$, which is smaller than was observed for the photoreceptoral-P3 loss $(-27 \%)$.

Inner retinal function can also be considered in terms of the oscillatory potentials, which are known to be sensitive indicators of anomalies in diabetic retinae. Figure $3 \mathrm{~A}$ shows that STZ treatment resulted in changes to the oscillatory potential waveform. The reduction in amplitude is particularly evident and is con-
Values are given $( \pm$ SEM) as means for each group. Alphanumerics indicate statistically significant differences between groups using ANOVA and comparison of means (Fischers PLSD $\alpha=0.05$ )
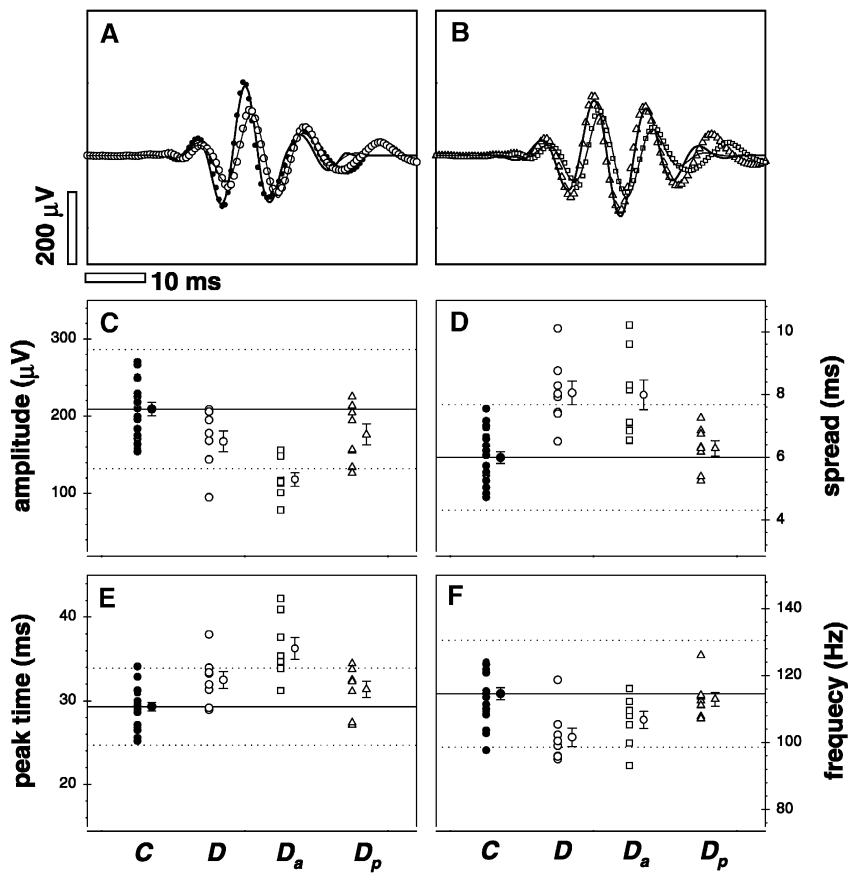

Fig. 3A-F. Oscillatory potentials (OPs) in diabetic rats. A Following conditioning and filtering, extracted OPs (symbols) are modelled using a GABOR (gaussian envelope with a sine wave carrier). Streptozotocin treated animals $(\bigcirc$, thin line) showed reduction of OP amplitude compared with control animals $(-$ thick line). B OP amplitudes were not significantly improved with either an ACE inhibitor (perindopril, $\triangle$, thick lines) or an inhibitor of advanced glycation end product formation (aminoguanidine, $\square$, thin lines). C STZ injection $(\mathrm{D}, \bigcirc)$ lowered OP amplitudes compared with controls $(\mathrm{C}, \mathrm{O})$. Perindopril $\left(\mathrm{D}_{\mathrm{p}}, \triangle\right)$ had no beneficial effect on OP amplitude, whereas aminoguanidine $\left(\mathrm{D}_{\mathrm{a}}, \square\right)$ induced a greater reduction of OP amplitude. Reference lines show mean (solid) and $95 \%$ confidence limits (dotted) of the mean control photoreceptoralP3 amplitude. D OP spread was greater in STZ animals. This effect was ameliorated by perindopril therapy, but not aminoguanidine. E OP peak time was delayed by STZ treatment. Perindopril therapy gave no improvement, whereas aminoguanidine exacerbated the effect. F OP frequency was reduced in STZ animals compared with controls. Perindopril, but not aminoguanidine, returned OP frequency back to within control levels 
firmed in Fig. 3C, which shows that oscillatory potential amplitudes are smaller $(p<0.05)$ in STZ rats (unfilled circles) compared with control rats (filled circles). Additionally, STZ oscillatory potentials were slower $(p<0.05 ; 32.5 \pm 1.0$ vs $29.5 \pm 0.7 \mathrm{~ms})$ and more spread $(p<0.001 ; 8.1 \pm 0.4$ vs $6.4 \pm 0.2 \mathrm{~ms})$ compared with control animals, which resulted in a lower frequency $(p<0.01 ; 101.6 \pm 2.7$ vs $111.3 \pm 2.4 \mathrm{~Hz})$. Consistent with the magnitude of postreceptoral-P2 amplitude reduction, oscillatory potentials showed an approximate change of $-19 \% \quad(167.2 \pm 13.6$ vs $205.2 \pm 4.5 \mu \mathrm{V}$ ), which is smaller than the photoreceptoral loss observed above.

Perindopril but not amino guanidine restores retinal function in STZ rats. We find that treatment with an ACE inhibitor ameliorates the functional deficits induced by STZ injection in rats. The representative raw data and photoreceptoral-P3 model fits in Fig. 1C shows that perindopril treatment (unfilled triangles, thick lines) gave larger photoreceptoral-P3 responses than aminoguanidine therapy (unfilled squares, thin lines). Fig. 1D and E confirms that perindopril returned photoreceptoral-P3 amplitudes back to control levels ( $\mathrm{C}$ vs $\left.\mathrm{S}_{\mathrm{p}} ; p=0.94\right)$. These amplitudes were better than untreated STZ $(p<0.0001)$ as well as aminoguanidine treated $(p<0.001)$ animals. Indeed, postreceptoral-P2 amplitudes extracted from aminoguanidine treated STZ animals were not significantly improved from untreated diabetic rats $(p=0.42)$. Importantly, perindopril and aminoguanidine when administered to control rats did not alter the electroretinogram.

Figures 2 and 3 show that perindopril treated (unfilled triangles) STZ animals benefited from improvement of postreceptoral-P2 amplitudes (Fig. 2B; $p<0.01$ ) and implicit times (Fig. $2 \mathrm{C} ; p<0.05$ ) compared with untreated STZ (unfilled circles). Perindopril enhanced these parameters to levels comparable to the control (filled circles) group (amplitude; $p=0.25$, implicit time; $p=0.17$ ). Perindopril treatment was unable to improve oscillatory potential amplitudes (Fig. 3C; $p=0.62$ ) or peak times (Fig. 3E; $p=0.46$ ) beyond the levels observed for the untreated STZ group. However, oscillatory potential spread (Fig. 3D; $p<0.0001$ ) and frequency (Fig. 3F; $p<0.01$ ) improved compared with untreated STZ rats. Hence, perindopril therapy in rats ameliorated the functional deficits induced by STZ induced diabetes. Such improvement was observed in both photoreceptor and inner retinal function.

Aminoguanidine therapy (unfilled squares) in STZ treated animals had no beneficial effect on either postreceptoral-P2 (Fig. 2B; $p=0.92$ ) or oscillatory potential (Fig. 3C; $p=0.62$ ) amplitudes compared with untreated STZ animals (unfilled circles). Indeed, aminoguanidine treatment appeared to make oscillatory potential amplitudes and peak times smaller (Fig. 3C; $p<0.05$ ) and slower (Fig. 3E; $p<0.001)$ respectively, compared with untreated STZ animals. However, an improvement was observed for postreceptoral-P2 implicit times as shown in Fig. $2 \mathrm{C}(p<0.05)$. The different therapeutic effects of perindopril and aminoguanidine could provide information as to the cause of the functional deficits observed in the diabetic retina.

\section{Discussion}

Our finding of reduced photoreceptoral-P3 and inner retinal amplitudes provides clear evidence that diabetes results in neural dysfunction. In this study, the photoreceptoral integrity was assayed at a time when little vascular change is manifest [19] and the response was analyzed in terms of the known biochemical cascade of phototransduction [23]. This approach showed that the saturated photoreceptoral-P3 amplitude was smaller in diabetic animals compared with control rats, whereas photoreceptoral sensitivity remains unaffected by diabetes.

Importantly, the reduction in photoreceptoral-P3 amplitude was similar if not greater than was observed for the inner retinal derived postreceptoral-P2 and oscillatory potentials. This outcome is consistent with the idea that inner retinal deficits can arise from photoreceptoral anomalies. A smaller photoreceptoral-P3 response would alter glutamate synaptic signalling and subsequently reduce ON-bipolar cell activation $[24,25]$. A similar mechanism can account for the reduction in oscillatory amplitude observed in this study. Additionally, the absence of any reduction in postreceptoral-P2 implicit time further supports the contention that the reduction in postreceptoral-P2 amplitude has a passive mechanism such as that described above.

The reduction in phototransduction amplitude may occur by one of several mechanisms, including: the presence of fewer photoreceptors, a reduced length of the photoreceptor outer segments, fewer cGMP gated cationic channels, or an altered transmembrane ionic gradient. Since anatomical studies of the diabetic rat retina provide no evidence for morphological change or a reduction in photoreceptor numbers, these factors are unlikely to underpin the losses observed in our animals. Additionally, there is no evidence for changes to non-specific cationic channels. In contrast, a reduced $\mathrm{Na}^{+}-\mathrm{K}^{+}$ATPase activity has been shown in diabetic rats [16]. $\mathrm{Na}^{+}-\mathrm{K}^{+}$ATPase function is responsible for sustaining trans-membrane ionic gradients, so a reduced capacity is consistent with our finding and provides a parsimonious explanation for the functional loss.

This loss is not surprising in a metabolic disease such as diabetes, as the retina has the highest metabolic demand of any tissue [26] and is known to show both vascular and neural compromise in diabetes [3, 27]. The majority of retinal oxygen consumption and 
adenosine triphosphate (ATP) production supports photoreceptoral function and in particular the dark current [26]. Transport of $\mathrm{Na}^{+}$via $\mathrm{Na}^{+}-\mathrm{K}^{+}$ATPases maintains the resting potential of photoreceptors and thereby the dark current, and accounts for nearly half of retinal ATP consumption. Light initiates the phototransduction cascade and reduces this dark current by closure of non-specific cationic channels to induce photoreceptor hyperpolarization, which is measured as the saturated photoreceptor amplitude $\left(\mathrm{Rm}_{P 3}\right)$ of the electroretinogram. Hence, $\mathrm{Na}^{+}-\mathrm{K}^{+}$ATPase activity is central to phototransduction and any perturbation in its activity will manifest as an altered phototransduction amplitude [28]. It is noteworthy that in diabetes, reduced $\mathrm{Na}^{+}-\mathrm{K}^{+}$ATPase activity is observed in a variety of different cell types [29], including those of the retina [16].

The basis for the decrease in $\mathrm{Na}^{+}-\mathrm{K}^{+}$ATPase activity is unclear and could be caused by altered enzyme kinetics and/or subunit expression. Abnormal expression of $\mathrm{Na}^{+}-\mathrm{K}^{+}$ATPase subunits has been reported in the cardiac muscle membranes of diabetic animals [29], although a change in expression does not seem to occur in the retina [16]. Nevertheless, it is established that the renin-angiotensin system (RAS) and, in particular, that angiotensin-II (AngII), can modulate $\mathrm{Na}^{+}-\mathrm{K}^{+}$ATPase activity [30]. The role of the RAS is complex, as AngII stimulates ionic pumps in smooth muscle cells and kidney by activating protein kinase cepsilon (PKC) [31]. As PKC is a well known modulator of $\mathrm{Na}^{+}-\mathrm{K}^{+}$ATPase activity [32], an increased $\mathrm{PKC}$ concentration in the diabetic rat retina [33] could contribute to the photoreceptoral dysfunction seen in our animals. These findings suggest that the RAS has a role in the development of diabetic neuropathy by its action either on PKC or directly on $\mathrm{Na}^{+}-\mathrm{K}^{+}$ATPases. Notwithstanding this, the nature of RAS involvement remains uncertain given that lowered angiotensin converting-enzyme (ACE) activity has been detected in the retina of diabetic rats, even with increased serum ACE [34].

In spite of conflicting evidence, we conclude that the RAS system must contribute in some way to retinal dysfunction in diabetic rats as ACE inhibition returns normal photoreceptoral and inner retinal amplitudes in the diabetic group. All physiological parameters were improved in the treated cohort, although only functional parameters were normalized to control levels. Perindopril treatment had no effect on parameters in control animals.

Perindopril is a potent antihypertensive drug, however we do not believe that a reduction in blood pressure underlies the functional improvement found with perindopril. In support of this contention, improvement of oscillatory potential deficits was only achievable using an ACE inhibitor, despite similar reductions in blood pressure with a calcium antagonist and a beta-blocker [35]. Instead, we posit that the effect involves an altered $\mathrm{Na}^{+}-\mathrm{K}^{+}$ATPase activity in the diabetic retina [34]. We note that the ACE inhibitor, captopril, is known to restore retinal $\mathrm{Na}^{+}-\mathrm{K}^{+}$ATPase activity in diabetic rats [16]. Specifically, captopril stimulates $\mathrm{Na}^{+}-\mathrm{K}^{+}$ATPase activity in the neural retina but not the retinal pigment epithelium of diabetic animals [36].

In order to consider the hypothesis that perindopril has a neuromodulatory action in the retina, we contrast its effect against that found with an inhibitor of advanced glycation end product (AGE) formation. Aminoguanidine, prevents glucose-dependent non-enzymatic AGE accumulation, which stops the activation of AGE specific receptors and subsequently reduces many deleterious actions including the formation of cytokines [37, 38]. However, aminoguanidine may have some neuroprotective actions through inhibition of nitric oxide formation [39, 40], as evidenced by the reduction in ganglion cell loss attenuated in an animal model of glaucoma [41]. Despite these benefits of aminoguanidine [38, 39, 40, 41], we were unable to show an improvement of functional amplitudes in diabetic rats, even though physiological parameters were improved. The absence of any functional improvement with aminoguanidine treatment provides indirect evidence for a lack of patent vasculopathy in our diabetic rats as this is the expected locus of aminoguanidine action. Moreover, the common physiological changes found with both drugs would imply some common vascular mechanism. These findings also suggest that perindopril ameliorates photoreceptor deficits in the diabetic retina through a neuromodulatory route rather than involving the vascular endothelium.

A caveat to this interpretation is that the lower blood pressure and $\mathrm{HBA}_{1 \mathrm{c}}$ levels that can occur with perindopril can contribute to the improved retinal function in this group of treated diabetic animals. We argue above that any improvement in blood pressure is likely to play a minor role. In contrast, improved hyperglycaemic control indicated by lower $\mathrm{HBA}_{1 \mathrm{c}}$ could contribute to the observed functional improvement, as the severity of diabetic complication has been associated with the degree of hyperglycaemia [42]. This issue requires further consideration as retinal function is normalized with perindopril treatment, while $\mathrm{HBA}_{1 \mathrm{c}}$ remains twice that of control animals.

Our study advances the outcomes of the HOPE [43] and EUCLID study group [44] multi-centre trials, which show that ACE inhibition lowers the risk of diabetic complications. Our findings suggest that ACE inhibition can directly modulate neuronal as well as vascular function. It also supports the proposal that early intervention in diabetics with ACE inhibitors will be a useful addition to current management strategies. 


\section{References}

1. Aiello LP, Gardner TW, King GL et al. (1998) Diabetic retinopathy. Diabetes Care 21:143-156

2. Mizutani M, Gerhardinger C, Lorenzi M (1998) Müller cell changes in human diabetic retinopathy. Diabetes 47:445449

3. Lieth E, Gardner TW, Barber AJ, Antonetti DA (2000) Retinal neurodegeneration: early pathology in diabetes. Clin Experiment Ophthalmol 28:3-8

4. Coupland SG (1987) A comparison of oscillatory potential and pattern electroretinogram measures in diabetic retinopathy. Doc Ophthalmol 66:207-218

5. Juen S, Kieselbach GF (1990) Electrophysiological changes in juvenile diabetics without retinopathy. Arch Ophthalmol 108:372-375

6. Falsini B, Porciatti V, Scalia G et al. (1989) Steady-state pattern electroretinogram in insulin-dependent diabetics with no or minimal retinopathy. Doc Ophthalmol 73:193200

7. Caputo S, Di Leo MA, Falsini B et al. (1990) Evidence for early impairment of macular function with pattern ERG in type I diabetic patients. Diabetes Care 13:412-418

8. Prager TC, Garcia CA, Mincher CA, Mishra J, Chu HH (1990) The pattern electroretinogram in diabetes. Am J Ophthalmol 109:279-284

9. Shirao Y, Kawasaki K (1998) Electrical responses from diabetic retina. Pro Ret Eye Res 17:59-76

10. Sakai H, Tani Y, Shirasawa E, Shirao Y, Kawasaki K (1995) Development of electroretinographic alterations in streptozotocin- induced diabetes in rats. Ophthalmic Res 27:57-63

11. Pautler EL, Ennis SR (1980) The effect of induced diabetes on the electroretinogram components of the pigmented rat. Invest Ophthalmol Vis Sci 19:702-705

12. Holopigian K, Greenstein VC, Seiple W, Hood DC, Carr RE (1997) Evidence for photoreceptor changes in patients with diabetic retinopathy. Invest Ophthalmol Vis Sci 38:2355-2365

13. Kurtenbach A, Wagner U, Neu A, Schiefer U, Ranke MB, Zrenner E (1994) Brightness matching and colour discrimination in young diabetics without retinopathy. Vision Res 34:115-122

14. Tregear SJ, Knowles PJ, Ripley LG, Casswell AG (1997) Chromatic-contrast threshold impairment in diabetes. Eye 11:537-546

15. Lieth E, Barber AJ, Xu B, Dice C, Ratz MJ, Tanase D, Strother JM (1998) Glial reactivity and impaired glutamate metabolism in short-term experimental diabetic retinopathy. Penn State Retina Research Group. Diabetes 47:815820

16. Ottlecz A, Bensaoula T (1996) Captopril ameliorates the decreased $\mathrm{Na}+\mathrm{K}(+)$-ATPase activity in the retina of streptozotocin-induced diabetic rats. Invest Ophthalmol Vis Sci 37:1633-1641

17. Chaturvedi N (2000) HOPE and extension of the indications for ACE inhibitors? Heart Outcomes Prevention Evaluation. Lancet 355:246-247

18. Nagisa Y, Shintani A, Nakagawa S (2001) The angiotensin II receptor antagonist candesartan cilexetil (TCV-116) ameliorates retinal disorders in rats. Diabetologia 44:883888

19. Su EN, Alder VA, Yu DY, Yu PK, Cringle SJ, Yogesan K (2000) Continued progression of retinopathy despite spontaneous recovery to normoglycemia in a long-term study of streptozotocin-induced diabetes in rats. Graefes Arch Clin Exp Ophthalmol 238:163-173
20. Hood DC, Birch DG (1990) A quantitative measure of the electrical activity of human rod photoreceptors using electroretinography. Vis Neurosci 5:379-387

21. Hood DC, Birch DG (1992) A computational model of the amplitude and implicit time of the b-wave of the human ERG. Vis Neurosci 8:107-126

22. Bui BV, Armitage JA, Vingrys AJ (2002) Extraction and modelling of oscillatory potentials. Doc Ophthalmol 104:17-36

23. Lamb TD, Pugh EN Jr (1992) A quantitative account of the activation steps involved in phototransduction in amphibian photoreceptors. J Physiol (Lond) 449:719-758

24. Slaughter MM, Miller RF (1981) 2-amino-4-phosphonobutyric acid: a new pharmacological tool for retina research. Science 211:182-185

25. Nawy S, Jahr CE (1990) Suppression by glutamate of cGMP-activated conductance in retinal bipolar cells. Nature 346:269-271

26. Ames A 3rd, Li YY, Heher EC, Kimble CR (1992) Energy metabolism of rabbit retina as related to function: high cost of Na+ transport. J Neurosci 12:840-853

27. Barber AJ, Lieth E, Khin SA, Antonetti DA, Buchanan AG, Gardner TW (1998) Neural apoptosis in the retina during experimental and human diabetes. Early onset and effect of insulin. J Clin Invest 102:783-791

28. Winkler BS (1983) Relative inhibitory effects of ATP depletion, ouabain and calcium on retinal photoreceptors. Exp Eye Res 36:581-594

29. Gerbi A, Maixent JM, Barbey O et al. (1998) Alterations of $\mathrm{Na}, \mathrm{K}-\mathrm{ATPase}$ isoenzymes in the rat diabetic neuropathy: protective effect of dietary supplementation with n-3 fatty acids. J Neurochem 71:732-740

30. Jacobi PC, Osswald H, Jurklies B, Zrenner E (1994) Neuromodulatory effects of the renin-angiotensin system on the cat electroretinogram. Invest Ophthalmol Vis Sci 35:973-980

31. Liu FY, Cogan MG (1990) Role of protein kinase C in proximal bicarbonate absorption and angiotensin signaling. Am J Physiol 258:F927-F933

32. Buhagiar KA, Hansen PS, Bewick NL, Rasmussen $\mathrm{HH}$ (2001) Protein kinase Cepsilon contributes to regulation of the sarcolemmal $\mathrm{Na}(+)-\mathrm{K}(+)$ pump. Am J Physiol Cell Physiol 281:C1059-C1063

33. Shiba T, Inoguchi T, Sportsman JR, Heath WF, Bursell S, King GL (1993) Correlation of diacylglycerol level and protein kinase $\mathrm{C}$ activity in rat retina to retinal circulation. Am J Physiol 265:E783-E793

34. Ottlecz A, Bensaoula T, Eichberg J, Peterson RG (1996) Angiotensin-converting enzyme activity in retinas of streptozotocin- induced and Zucker diabetic rats. The effect of angiotensin II on $\mathrm{Na}+\mathrm{K}(+)$-ATPase activity. Invest Ophthalmol Vis Sci 37:2157-2164

35. Cosenzi A, Bocin E, Sacerdote A et al. (1999) Antihypertensive drugs and the nervous system: ACE-inhibitors restore oscillatory potentials in hypertensives. Clin Exp Hypertens 21:223-231

36. Bensaoula T, Ottlecz A (2001) Biochemical and ultrastructural studies in the neural retina and retinal pigment epithelium of STZ-diabetic rats: effect of captopril. J Ocul Pharmacol Ther 17:573-586

37. Cooper ME, Bonnet F, Oldfield M, Jandeleit-Dahm K (2001) Mechanisms of diabetic vasculopathy: an overview. Am J Hypertens 14:475-486

38. Giardino I, Fard AK, Hatchell DL, Brownlee M (1998) Aminoguanidine inhibits reactive oxygen species formation, lipid peroxidation, and oxidant-induced apoptosis. Diabetes 47:1114-1120 
39. Tilton RG, Chang K, Hasan et al. (1993) Prevention of diabetic vascular dysfunction by guanidines. Inhibition of nitric oxide synthase versus advanced glycation endproduct formation. Diabetes 42:221-232

40. Du Y, Smith MA, Miller CM, Kern TS (2002) Diabetesinduced nitrative stress in the retina, and correction by aminoguanidine. J Neurochem 80:771-779

41. Neufeld AH, Sawada A, Becker B (1999) Inhibition of nitric-oxide synthase 2 by aminoguanidine provides neuroprotection of retinal ganglion cells in a rat model of chronic glaucoma. Proc Natl Acad Sci USA 96:9944-9948
42. Klein R (1995) Hyperglycemia and microvascular and macrovascular disease in diabetes. Diabetes Care 18:258268

43. Hoogwerf BJ, Young JB (2000) The HOPE study. Ramipril lowered cardiovascular risk, but vitamin E did not. Cleve Clin J Med 67:287-293

44. Chaturvedi N, Sjolie AK, Stephenson JM et al. (1998) Effect of lisinopril on progression of retinopathy in normotensive people with type 1 diabetes. The EUCLID Study Group. EURODIAB Controlled Trial of Lisinopril in Insulin-Dependent Diabetes Mellitus. Lancet 351:28-31 